\title{
AMEAÇA E CARÁTER TRANSNACIONAL DO NARCOTRÁFICO NA AMAZÔNIA BRASILEIRA
}

\author{
THREAT AND TRANSNATIONAL CHARACTER IN BRAZILIAN AMAZON'S \\ NARCOTRAFFIC
}

\section{Aiala Colares COUTO ${ }^{1}$}

\section{RESUMO}

$\mathrm{Na}$ atualidade, verifica-se que o crime organizado vem fragilizando a lógica de proteção e defesa das fronteiras dos Estados nacionais. E, nesse contexto, a Amazônia brasileira tornou-se uma rota primária obrigatória para a organização em redes do tráfico de cocaína de origem Andina em direção aos principais mercados consumidores. O objetivo aqui é analisar o caráter transacional do narcotráfico na Amazônia brasileira que destaca a existência de uma geografia do crime a partir de conexões regionais-globais que se dão sobre a região. A metodologia da pesquisa pautou-se em: revisão bibliográfica, análise de documentos, trabalhos de campo, observações sistemáticas e entrevistas.

Palavras-chave: Narcotráfico. Transnacional. Amazônia.

\begin{abstract}
Nowadays, it was found that organized crime, in the past decades, has been fragilizing the logic of protection and defense of the frontiers of the national States. And, in this context, Brazilian Amazon has become an obligatory primary route for the networks organization of the cocaine trafficking, of Andean origin, towards the main consumer markets. The objective of this work is to analyze the transnational character of narcotraffic in the Brazilian Amazon, which highlights the existence of a crime geography from regional-global connections that happen over the region. The research methodology was based on bibliographic revision, documents analysis, field works, systematic observations and interviews.
\end{abstract}

Keywords: Narcotraffic. Transnational. Amazon.

\section{INTRODUÇÃO}

As redes ilegais do narcotráfico necessitam de uma ampliação de sua escala de atuação em cadeias e, a partir disso manifestam estratégias de produção, distribuição e consumo da droga. A Geografia busca explicar a importância atual da Amazônia brasileira para as rotas do tráfico internacional de drogas, principalmente a partir de sua dimensão territorial que lhe coloca na condição de área de vazão de cocaína de origem andina para os mercados europeus, africanos e da região sul e sudeste do Brasil.

Por muito tempo a Amazônia vem despertando interesses associados à sua importância no cenário geopolítico global e que trata de questões de ordem ecológico-ambiental,

\footnotetext{
${ }^{1}$ Geógrafo. Professor e Pesquisador do Departamento de Geografia da Universidade do Estado do Pará (UEPA). E-mail: aialacouto@uepa.br
} 


\section{Aiala Colares COUTO}

sustentadas pelo discurso da preservação-sustentabilidade. Becker (2004) ao falar sobre a mercantilização da natureza, destacou três tipos de mercados que despertam as ambições sobre a região: o mercado do ar, da água e o da vida (biodiversidade).

O mercado do ar refere-se à ampliação de políticas de "sequestro" de carbono, no qual o desenvolvimento de projetos de reflorestamento permite a venda de taxas de emissão de Gás Carbônico (CO2) no mercado das bolsas de valores. O mercado da água trata do valor atribuído a água potável definida por Becker (2004) como o "ouro azul”, considerando as tendências recentes de escassez de água potável no planeta. A Amazônia, portanto, e sua importante reserva torna-se parte integrante de uma hidropolítica que desperta ambição do capitalismo central. Por fim, o mercado da vida, no qual a autora destaca o papel que a biodiversidade da floresta desempenha na possibilidade de desenvolvimento de pesquisas do ramo da farmacologia, ou mais ainda, a biodiversidade dá condições para a expansão da fronteira biotecnológica (BECKER, 2004).

Além desses problemas de ordem político-econômica que o Brasil enfrenta na região, tem-se também, questões de ordem ilícita em suas fronteiras, pois o desafio da segurança regional é o Estado brasileiro conseguir dar conta de monitorar as fronteiras da Amazônia com os seus países vizinhos, em especial aqueles que estão no mapa da Pan-amazônia ${ }^{2}$ e que se destacam pela produção de cocaína.

Dessa forma, surge um contexto conflitivo entre o limite e a fronteira, visto que, o limite do território brasileiro não se limita às fronteiras da região amazônica, e isso possibilita relações transfronteiriças que permitem a existência de fluxos cotidianos de pessoas, capitais, mercadorias e informações, fazendo com que também se manifestem atividades como contrabando, biopirataria, tráfico de pessoas, lavagem de dinheiro e o tráfico de drogas. De todo modo, pode-se dizer que essa "invasão" a partir das fronteiras fragiliza as políticas de segurança, deixando aspectos negativos na economia, na política e na cultura. Por isso, Hobsbawn (2007, p. 135) destaca que o terrorismo e o narcotráfico são (...) os dois grupos de enfrentamento em destaque nessa "nova" conflitividade.

Tal cenário insere a Amazônia internacional em um contexto de novos conflitos do século XXI, transformando-se em questão que envolve os países da América do Sul que tem

\footnotetext{
${ }^{2}$ Por Pan-Amazônia define-se a área internacional da floresta tropical que abrange o território de nove países ao Norte da América do Sul: Bolívia, Brasil, Colômbia, Equador, Guiana, Guiana Francesa, Peru, Suriname e Venezuela. Para além de definições normativas, o adjetivo "Pan-Amazônia" abrange as lutas de coletividades tradicionais, especialmente indígenas, desses países em torno de uma agenda comum para a proteção e preservação da região.
} 


\section{Aiala Colares COUTO}

em seus territórios uma porção de Amazônia, especialmente Bolívia, Colômbia e Peru, países que ainda se mantém como grandes produtores de coca e detentores de cartéis do tráfico de drogas.

Os limites transfronteiriços desses países com o Brasil, permitem o estabelecimento de relações entre as organizações do crime pelas transações comerciais do transporte da droga e criam configurações espaciais necessárias aos fluxos de cocaína que acompanham a dinâmica do modo de produção capitalista. Para Telles (2010, p. 161),

Além do mais, é nesses termos - e esse é o ponto - que as economias vêm se estruturando, esse é um dado também estruturante das hoje redefinidas relações entre Estado, economia e sociedade em tempos de globalização. A rigor, essa indistinção entre o legal e o ilegal, o lícito e o ilícito, o oficial e o paralelo já compõe o estado de coisas, na justaposição das redes (políticas, econômicas, nacionais e transacionais) e as atividades ilícitas.

De acordo com o relatório de 2016 do Escritório das Nações Unidas Sobre Drogas e Crimes (UNODC), a "economia das drogas 3 " apresenta-se enquanto uma verdadeira indústria que, na última década do milênio, chegou a faturar US\$ 870 bilhões. Nestes termos, a concentração no comércio do tráfico de drogas chega a $1,5 \%$ de todas as riquezas que são produzidas e que correspondem ao Produto Interno Bruto (PIB) mundial, e, portanto, chega a movimentar $40 \%$ das outras atividades ilegais lucrativas do crime organizado, tais como tráfico de armas, tráfico de pessoas e lavagem de dinheiro.

O fato é que as relações entre o lícito e o ilícito, constituem um fenômeno transversal na experiência contemporânea. São vários os autores que vem chamando a atenção para a transitividade entre o informal, o ilegal, e o ilícito, com uma preocupação, mais ou menos explicitada, em distinguir a natureza da transgressão que se opera no âmbito da economia informal ou, então, a que define as atividades ilícitas ou criminosas, como tráfico de drogas, armas e seres humanos (TELLES, 2010).

A UNODC (2014) aponta também que no Brasil houve um crescimento do consumo de cocaína, o que, de certa forma, é favorecido pela sua localização geográfica, pelo aumento do poder de compra da população e pela conectividade existente entre organizações criminosas como o Primeiro Comando da Capital (PCC), o Comando Vermelho (CV) e, mais recentemente, a Família Do Norte (FDN), com os cartéis Colombianos.

\footnotetext{
${ }^{3} \mathrm{O}$ que pode ser denominado de "Economia das Drogas" engloba um fenômeno de complexas relações sociais de produção que consolidam um tipo de acumulação capitalista em torno de um setor que apresenta especificidades atreladas à clandestinidade e a particularidades associadas a cada mercadoria e semelhanças a outras indústrias e setores da economia formal (SOUZA, 2015).
} 


\section{Aiala Colares COUTO}

Este tipo de organização torna-se, portanto, uma espécie de empresa multinacional do tráfico de drogas, com mecanismos e estruturas de poder consolidados, com atores cujas funções são bem definidas e os espaços de atuação bem delimitados, os quais obedecem a comandos hierárquicos que relacionam as redes externas e internas do crime organizado.

De fato, a Amazônia brasileira é uma rota primária obrigatória dos fluxos de cocaína que se direcionam para a Europa e a África através de redes que se formam a partir da conexão do Brasil com as Guianas, o Suriname e os demais países Andinos. E a bacia amazônica torna-se necessariamente um corredor de transporte, especialmente de cocaína que alimenta, inclusive, o mercado brasileiro.

A vulnerabilidade fronteiriça que a região enfrenta associada à pobreza da população que facilita o assédio de narcotraficantes em relação aos ribeirinhos que desenvolvem a função de mulas ou de guias sobre os rios da Amazônia completam a função do Brasil, um país que beneficia, distribui e consume a cocaína de origem andina.

Logo, a ação das redes do narcotráfico na Amazônia torna-se uma das mais significativas e preocupantes ameaças às fronteiras da região e ao debate sobre soberania nacional. Visto que, essas redes ilícitas criam estruturas de poder que conectam o local e o global nas relações transnacionais do comércio de drogas, de forma que estas redes têm na região suas articulações e bases operacionais, territorializando-se e articulando-se em facções ou comandos do crime organizado, os quais controlam as principais rotas de interesse do circuito espacial de distribuição, beneficiamento e consumo da droga.

\section{A AMAZÔNIA FACE ÀS AMEAÇAS TRANSNACIONAIS}

No atual contexto da globalização-fragmentação contemporânea os Estados nacionais enfrentam tensões e conflitos relacionados às ameaças transnacionais que forçam a uma política de fechamento e controle das fronteiras que em muito contrapõe o próprio processo de globalização. Destacam-se como novas ameaças do século XXI o terrorismo, o tráfico de pessoas e órgãos, o contrabando de armas e o narcotráfico global.

Não se assume aqui, a ideia de que essas atividades criminosas não existiam no século XX, contudo, o fim da Guerra Fria (1945-1991) que culminou com a vitória do capitalismo global orientado pelas aberturas dos mercados, permitiu também, o fortalecimento de atividades do crime organizado que fragilizam as políticas de segurança interna de muitos países, gerando inclusive, vários problemas de ordem social que forçam à criação de leis mais rígidas de combate ao crime. Por outro lado, o crime global tornou-se essa ameaça 


\section{Aiala Colares COUTO}

transnacional, sobretudo, devido o grande volume de capital gerado pelo seu comércio e que se institucionaliza através de paraísos fiscais e sistemas de corrupção presentes nas estruturas sociopolíticas de alguns países, atribuindo assim, um caráter institucional para o crime organizado.

Sobre o narcotráfico internacional, principalmente o tráfico de cocaína, é preciso compreender que as redes que organizam essa atividade econômica para o dito "mercado da droga" desestruturam as bases políticas internas dos Estados e por isso tornam-se ameaças vindas de uma organização que relaciona local e global não respeitando os limites instituídos pelo Estado.

Para Castells (1996), nas últimas décadas, as organizações criminosas vêm estabelecendo cada vez mais operações transnacionais, aproveitando-se da globalização econômica e de novas tecnologias de comunicação e transportes. Para este autor, a estratégia utilizada consiste em instalar suas funções de gerenciamento e produção em áreas de baixo risco, as quais detêm relativo controle do meio institucional. Dessa forma, volta-se a atenção às áreas com demanda mais afluente, de modo que possam cobrar preços mais elevados.

\footnotetext{
Por outro lado, assim como o processo produtivo em que empreendimentos lícitos estão inseridos, a mercadoria comercializada no tráfico ilegal de drogas também atravessa diversas fases de produção e, além disso, o próprio mercado como um todo está sujeito às dinâmicas políticas e econômicas do cenário internacional e baseado na lógica da oferta e da demanda. Dessa forma, com a intensificação dos fluxos de bens de consumo, de pessoas e de capital acarretada pela globalização, principalmente a partir da década de 1970, o tráfico internacional de drogas, seguindo a ordem política e econômica vigente, também se globalizou (PROCÓPIO FILHO; VAZ, 1997, p. 99).
}

Nestes termos, o narcotráfico apresenta-se enquanto um fenômeno bastante complexo e de difícil monitoramento, por esse motivo Santana (1999, p. 101) o define como uma "empresa transnacional dedicada ao tráfico de drogas ilegais que não paga impostos e gera os maiores lucros". São justamente esses lucros que tornam a economia do narcotráfico altamente competitiva dentro de esquemas envolvendo lavagem de dinheiro, por exemplo.

Sendo assim, ao expandir seus interesses econômicos e políticos, os grupos desenvolvem-se e tornam-se mais ramificados, aumentando o próprio mercado e o número de aliados. Além disso, engajam-se normalmente em outras atividades criminosas, tais como: o tráfico de pessoas e de órgãos, assassinatos, sequestros, a fim de preservar a própria segurança 


\section{Aiala Colares COUTO}

e a de seus negócios. Esse desenvolvimento faz dos grupos verdadeiras empresas de crime organizado, que possuem agências políticas e econômicas próprias (MANWARING, 2007).

A ameaça transnacional do tráfico de drogas é, sem dúvida, alguma espécie de "inimigo invisível" que coloca em risco a soberania dos Estados nacionais. A característica empreendedora dessa atividade econômica ilícita, ao se fortalecer, consegue ampliar sua escala de atuação em níveis locais, nacionais e internacionais. Nas palavras de Rodrigues (2012, p. 7), “a inquietação causada por essa prática proibida é intensa porque ela é apresentada como um inimigo sem rosto, uma força potente e difusa difícil de ser localizada e que se oculta como um animal ardiloso".

O Brasil ao cumprir uma dupla função no contexto do narcotráfico (área de trânsito e mercado) dá condições para que os interesses geoestratégicos do crime organizado se direcionem para a Amazônia brasileira. Assim, "os circuitos por onde circulam os produtos até chegarem aos mercados populares nos centros urbanos fazem o traçado das verdadeiras redes transnacionais de trocas informais nas fronteiras porosas do legal e ilegal, sempre tangenciando os mercados ilícitos (drogas, armas, seres humanos)” (TELLES, 2010, p. 179).

Também no Brasil, o narcotráfico está territorializado nas favelas e nas periferias das grandes cidades, onde é possível encontrar todo e qualquer tipo de conflito pelo uso do território. Além disso, segundo os dados sobre o sistema carcerário brasileiro, do Ministério da Justiça de 2013, no país há uma população carcerária de 622.202 pessoas, sendo 138.366 pessoas presas pelo crime de tráfico de drogas; o que representa uma grande parcela de indivíduos presos por esse tipo de crime. O Brasil possui a quarta maior população carcerária do mundo, ficando atrás de EUA (2,2 milhões), da China (1,65 milhões) e da Rússia (644 mil), e a maioria desses encarcerados são jovens negros de baixa escolaridade, de acordo com esses dados.

A grande questão é que o narcotráfico na Amazônia impôs um tipo de geoestratégia que potencializa diferentes etapas do comércio de produção, distribuição e consumo da cocaína. Ou seja, para a região foi atribuída uma função que está vinculada a uma divisão internacional do trabalho criada a partir das necessidades do tráfico internacional de drogas. Sendo assim, a enorme área de trânsito para o escoamento de cocaína que a Amazônia brasileira passou a representar para as facções do crime organizado internamente criam conflitos que se dão a partir das buscas de facções nacionais pelo controle das principais rotas que abastecem os mercados brasileiros, europeus e africanos. 


\section{Aiala Colares COUTO}

Então, o narcotráfico na Amazônia, neste início de século, destaca-se enquanto uma das mais significativas e preocupantes ameaças à soberania nacional, de forma que, suas redes criam estruturas de poder que utilizam algumas cidades da região como espécie de bases operacionais que se tornam espécies de territórios em redes de um circuito espacial do narcotráfico. O narcotráfico cria suas "redes superpostas e embaralhadas de pessoas, trocas, produtos, bens que circulavam nas fronteiras incertas do informal e ilegal, entre expedientes de sobrevivência, o trabalho irregular, pequenos empreendimentos locais e os "negócios do crime" a gravitar em torno dos pontos de venda de drogas ilícitas [...]” (TELLES, 2010, p. 198).

Porém, sempre é bom resgatar a interpretação acerca da mudança de comportamento do Brasil em relação ao comércio global de cocaína, pois essa incômoda colocação que nos deixa em segundo lugar no ranking dos maiores consumidores, obrigatoriamente estrutura $\mathrm{o}$ mercado da droga a partir da presença de organizações do crime organizado: Comando Vermelho (CV), Amigos dos Amigos (ADA), Terceiro Comando (TC), do Rio de Janeiro; Primeiro Comando da Capital (PCC), de São Paulo; e Família do Norte (FDN), localizada no estado do Amazonas. Essas são facções altamente organizadas e conectadas aos principais fornecedores da droga para o Brasil, nesse caso (VÍRGULA) os países da Comunidade Andina. E a Amazônia tornou-se então, região de cobiça e interesse do crime organizado nacional-global, dada sua importância para o mercado da droga, seja ele nacional ou mundial.

\section{O CARÁTER TRANSNACIONAL DO TRÁFICO DE DROGAS NA AMAZÔNIA}

Os problemas enfrentados pela região amazônica são os mais diversos e complexos presentes numa região geográfica. Desde o processo de integração nacional com as políticas de desenvolvimento regional (pós anos de 1960), a Amazônia tornou-se o que ficou definido pela geógrafa Bertha Becker (1999) como uma "região de fronteira", ou seja, no entendimento da autora, um espaço aonde o capital não está consolidado.

Vários projetos desenvolvimentistas foram direcionados para a região como: expansão das madeireiras, agropecuária, mineração, políticas de assentamentos rurais, hidrelétricas, rodovias e telecomunicações. Contudo, o olhar de "fora" para "dentro" ou o olhar sobre a região, transformaram a Amazônia em um dos espaços mais violentos e tensos do planeta.

A região convive com a permanência do trabalho considerado em condições análogas á escravidão, conflitos agrários com a presença de milícias armadas no campo a serviços de fazendeiros, problemas ambientais causados pelo descontrole da expansão agropecuária sobre 


\section{Aiala Colares COUTO}

a floresta (pasto e soja), além da atividade mineradora que promove problemas de ordem socioambiental, como por exemplo, a contaminação dos rios e os riscos para a saúde das comunidades tradicionais ribeirinhas da Amazônia.

Somando-se a estes fatos, a região amazônica ainda enfrenta as ações vinculadas à economia do crime, aquelas em redes que desafiam o poder do Estado como o narcotráfico por exemplo. Entretanto, o narcotráfico se destaca também por ser um dos principais problemas da Amazônia colombiana, equatoriana e peruana. Como o Brasil exerce um importante papel para o circuito espacial-global das redes do narcotráfico, a faixa de fronteira com os países andinos, torna-se uma zona de instabilidade geopolítica, devido principalmente, a existência desses corredores da droga na Amazônia.

Kolk (1996) chama a atenção para o fato de que na fronteira da Amazônia brasileira com os seus vizinhos, tem-se uma área de baixo grau de desenvolvimento econômico e social. Fatores característicos da região, tais como uma baixa densidade demográfica em parcela significativa do território, a atuação precária do Estado na oferta de serviços públicos, contribuem para o surgimento de zonas de instabilidade na fronteira, convivendo com meândricas peculiaridades ecológicas.

Com a intensificação das atividades criminosas do narcotráfico na fronteira e em parcelas da região, o crime global das redes ilegais passou a gerar perdas políticas e econômicas significativas aos países envolvidos. Nesse contexto, as articulações advindas das ações do narcotráfico induzem a acreditar que, de fato, falta uma política legítima por parte dos governos nacionais de forma a procurar minimizar estas ações ilícitas decorrentes dessa atividade, como por exemplo, uma maior regulação e fiscalização das fronteiras desses países, justificando com isso uma "contenção territorial" (HAESBAERT, 2014).

Dessa forma, concorda-se com Haesbaert e Gonçalves (2005, p. 64), quando afirmam que "o comércio de drogas ilícitas tem caráter de atividade transnacional, opera em escala global, mas seus lucros dependem da localização geográfica dos lugares de produção e de consumo, da existência de fronteiras nacionais e da legislação de cada estado nacional". Para Martins (1997, p. 11), a fronteira de modo algum se resume à fronteira geográfica. Ela é fronteira de muitas e diferentes coisas: fronteira da civilização (demarcada pela barbárie que nela se oculta), fronteira espacial, fronteira de culturas e visões de mundo, fronteira de etnias, fronteira da história, da historicidade do homem e, sobretudo, fronteira do humano.

Sendo assim, a segurança, por sua vez, assume um caráter transnacional, sobretudo na conexão das agências de diversos países. Entende-se, então, que o inimigo não é mais um 


\section{Aiala Colares COUTO}

estado estrangeiro, mas organizações estruturadas em rede, fundadas em critérios de solidariedade que pouco tem a ver com o sentimento de 'pertencimento' a um Estado Nacional (terrorismo, narcotráfico, imigração ilegal, entre outros) (MACHADO, 2000).

Para Machado (1998), estudos já destacavam que nas últimas décadas do século XX, as redes que mais obtiveram relativo sucesso em fazer uso da bacia amazônica sul-americana como unidade funcional e como região geográfica foram as firmas e empreendimentos que exploram o comércio ilegal de drogas e contrabando de mercadorias.

A Amazônia é vista como um espaço singular para a firmação de um mercado da droga presente no Brasil e nos países da África e da Europa que são destinos da cocaína que chega até eles passando pelo Brasil e, em seguida, pela Amazônia. De acordo com Procópio Filho e Vaz (1997, p. 78):

Em razão de se constituir em atividade de caráter transnacional e por seu enfrentamento ser objeto de políticas, inclusive de cooperação internacional, e ainda pelas peculiaridades do envolvimento do Brasil no fenômeno do tráfico internacional de drogas ilícitas, o estudo de sua sociologia, no caso brasileiro, necessita a contextualização da análise política de seus condicionantes regionais internos no âmbito das relações internacionais.

Esse caráter transnacional que o narcotráfico tem como característica é, de fato, um dos pontos fundamentais da organização reticular que lhe dá uma estrutura política e econômica capaz de manter a atividade e promover uma manutenção capaz de tornar volátil a própria movimentação das redes. Logo, a movimentação depende do grau de conectividade e acessibilidade aos principais mercados do Brasil e do mundo.

Hoje o narcotráfico é um problema de caráter emergencial que põe sobre risco a instabilidade política da região. Visto que, constantemente deixa as fronteiras da Amazônia em estado de total alerta, por isso, o projeto SIPAM (Sistema de Proteção da Amazônia) também foi idealizado para o combate ao tráfico de drogas nas fronteiras, destacando que:

A produção, o tráfico e o uso indevido de drogas têm alcançado grande magnitude internacional. $\mathrm{O}$ narcotráfico tem adquirido conotações particulares, pois a ilegalidade da indústria da droga induz a geração de aspectos peculiares, tais como, o crime organizado, a violência e a corrupção, que acabam por tramitar pela sociedade como valores naturais, pertinentes ao funcionamento normal do Estado (MARINHO, 2008, p. 173).

As áreas escolhidas têm um sentido geográfico para chegar até os principais nós das redes e principais mercados do país, o que força narcotraficantes a optarem por rotas e cidades estratégicas. Entretanto, estas são redes dinâmicas e que podem eleger novas rotas de acordo 


\section{Aiala Colares COUTO}

com as necessidades de organização e isso faz com que as redes sejam flexíveis caso haja necessidade de fugir das fiscalizações. O mapa a seguir faz uma referência das rotas organizadas em redes pelo tráfico de drogas na região amazônica considerando, por exemplo, as chamadas "novas rotas", segundo a Polícia Federal do Brasil e as informações coletadas em campo durante o processo investigativo desta pesquisa.

Mapa 1. Redes e fluxos do narcotráfico na Amazônia

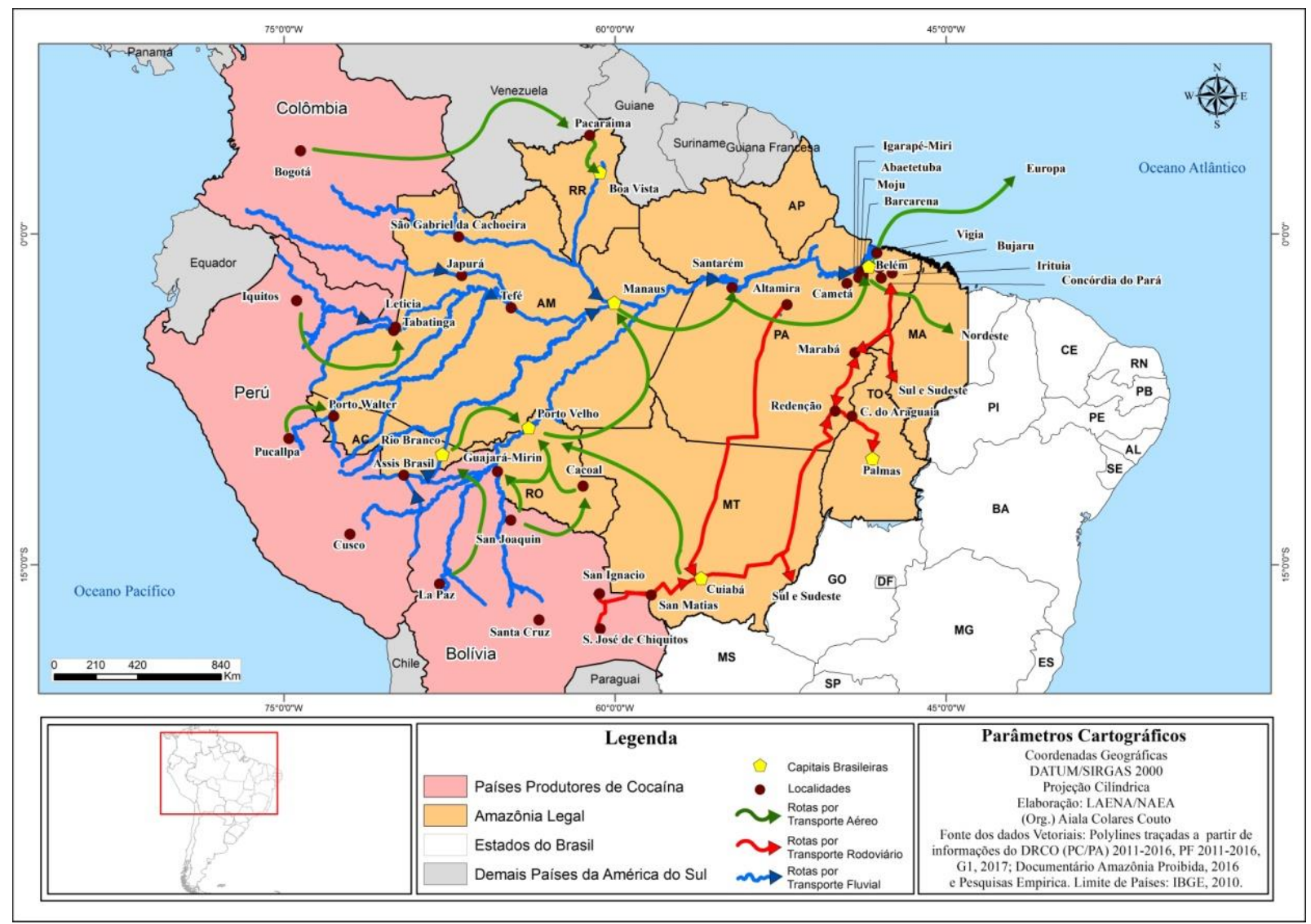

Fonte: Polícia Federal/Pesquisa de Campo (2016).

De acordo com o Mapa acima, existem várias rotas que conectam a Amazônia Brasileira aos países da Comunidade Andina. Na Bolívia, por exemplo, a conexão se dá com o estado do Mato Grosso, onde são utilizadas as rotas terrestres e aéreas, por meio de uma articulação reticular que leva a droga do Oeste do Pará para a região do Xingu, a partir do município de Altamira, Sudeste do Pará, até os municípios de Conceição do Araguaia, Redenção, Marabá e para o Norte do Tocantins até Palmas, chegando até o Sudeste do Brasil. Da Bolívia também partem os fluxos de cocaína, que vão em direção ao estado de Rondônia, o qual recebe transportes aéreos e fluviais. Destaca-se que os traficantes constroem pistas de 


\section{Aiala Colares COUTO}

pouso clandestinas no meio da floresta, ou então, utilizam fazendas como fachadas, segundo o relato de policiais federais.

Do Peru para a Amazônia brasileira prevalecem as rotas fluviais em direção aos estados de Rondônia e Acre; do estado do Amazonas em direção ao rio Amazonas e seus afluentes da margem direita. Nesse arco, as cidades de São José Chiquitos, San Ignacio, San Matias, Guajará Mirin e a capital La Paz, todas na Bolívia, funcionam como nós ou nexos conectados que dão sentido a toda a estrutura espacial em redes e chega até às cidades da Amazônia, sem respeitar os limites fronteiriços. As cidades de Cusco, Pucallpa e Iquitos, no Peru, são os nexos das redes; no arco Central e Sul da fronteira, com forte integração com o estado do Amazonas pelos rios, destacam-se as cidades de Porto Walter e Assis Brasil no Acre.

Na Colômbia, Bogotá é o centro de comando e precisa de articulações por toda a fronteira com o Brasil. Para isso, as cidades de Letícia, na fronteira com Tabatinga (Brasil), são a cidades gêmeas que sofrem atenção especial, sobretudo, dos órgãos fiscalizadores. Ainda há Japurá e São Gabriel da Cachoeira no estado do Amazonas, cidades que também dão sentido e dinamismo para as redes do tráfico de drogas na região. E, finalmente, completando esse processo pelos arcos da parte Norte da Amazônia, a conexão de Bogotá até Pacaraima e Boa Vista passando pela Venezuela.

A organização do narcotráfico na Amazônia brasileira envolve um conjunto de cidades que sofrem influência das relações de poder de narcotraficantes e facções que estão associadas aos narcotraficantes estrangeiros de países como Bolívia, Colômbia e Peru. Neste aspecto, torna-se necessário que os grupos no Brasil deem condições de que a droga possa fluir com facilidade nos mercados brasileiros e possa chegar até os mercados europeus e africanos.

A Amazônia apresenta uma bacia hidrográfica que se espraia para além dos limites do território brasileiro. $\mathrm{O}$ ambiente social com áreas de baixas densidades demográficas, em meio a uma floresta densa e a variedade de rios, torna o ambiente proveitoso para os narcotraficantes que se aproveitam dessas peculiaridades regionais. Sob o ponto de vista do Estado, há maior dificuldade em se exercer políticas de comando e controle das redes ilegais. Por outro lado, para os agentes das redes ilegais, essas características tornam-se facilitadoras do repasse de mercadorias contrabandeadas, biopiratarias e o próprio tráfico de drogas.

É nesse ambiente de enorme proporção territorial e de baixa densidade demográfica, onde a ausência do Estado chega a ser uma regra e não uma exceção, que identificamos a ação de grupos adversos que se aproveitam da 


\section{Aiala Colares COUTO}

densa floresta para acobertar inúmeras atividades ilícitas, utilizando-se de rotas aéreas, terrestres e fluviais clandestinas para transportar toda sorte de droga, contrabando, armas e munições (ISHIDA, 2006, p. 4).

Preferiu-se utilizar aqui o termo atuação precária ao invés de "ausência do estado", visto que não se acredita neste total afastamento, pois de uma forma ou de outra, ele está presente. É claro que estas ameaças impostas sobre o espaço amazônico legitimam, quando necessário, o "estado de exceção", em nome da segurança e da defesa, pois as leis de exceção tornam-se regras, nas quais o ilegítimo torna-se legítimo. Julga-se também a extrema ameaça representada por estas atividades ilegais que são utilizadas como discurso. Além disso, considera-se que os projetos Sistema de Proteção da Amazônia (SIPAM) e Calha Norte são exemplos de que esta ausência de Estado não existe e de que a qualquer momento o "estado de exceção" pode estar em ação. Para Haesbaert (2008, p. 33):

Esses processos, na verdade, mais do que um simplista refortalecimento do papel do Estado, estão inseridos dentro "de uma lógica contraditória e ambivalente, na medida em que, se por um lado parece revelar seu fortalecimento, como o recurso frequente a 'Estado de exceção', por outro pode estar justamente revelando o seu caso, no desespero de tentativas de controle que buscam, de certa forma, controlar o incontrolável".

Esse jogo de des-controle de território, no qual a Amazônia participa, explica a complexidade de se poder ter uma noção mais precisa sobre as relações institucionais do narcotráfico na região. O que se verifica é que ele impõe uma territorialização que pode ser interpretada como uma possível desterritorialização do estado.

Essa nova-velha des-territorialização, direta ou indiretamente levada a cabo pelo Estado (seja dentro da "norma" vigente, seja por meio de legalização do ilegal ao criar novos "campos" que podem se confundir com o próprio Estado como um todo), aparece acoplada a diversas outras iniciativas, principalmente as desse aparato a-legal que a "ausência" ou fragilização do papel social do Estado incitou a emergir, como no caso dos territórios dominados por máfias e/ou pelo narcotráfico. Parece tratar-se agora, sobretudo, do controle dessa massa crescente de despossuídos (HAESBAERT, 2014, p. 33).

Assim, a Amazônia está em meio a um conflito que evidencia que o Estado e as organizações ilegais têm interesses divergentes (ora convergentes) sobre o uso do território. Já que está sendo tratado sobre as organizações ilegais, é preciso reconhecer que nestas condições elas dependem também de microrrelações criadas por micropoderes capazes de se 


\section{Aiala Colares COUTO}

estruturarem em termos de organizações territoriais zonais e reticulares, os quais estarão presentes nas cidades da região e farão parte das redes macros. Nestes termos:

Não podemos, entretanto, ficar de tal forma obcecados por esse macropoder do Estado ou das grandes organizações ilegais a ponto de ignorar os micropoderes, como diria Foucault, em que não apenas esse macropoder é legítimo e outros micropoderes heterônomos brotam com igual força, mas também em que podem ser gestados movimentos sociais de resistência, articuladores de territórios/territorialidades mais alternativos ou mais autônomos. Ao priorizar a multiplicidades de sujeitos que fazem a história, e as resistências que eles constroem, podemos entender a multiplicidade de territórios/territorialidades possível de ser desenhada, numa visão muito mais complexa da relação entre poder e espaço, dentro do movimento contemporâneo de desterritorialização do Estado (HAESBAERT, 2014, p. $34)$.

As organizações criminosas internacionais esquematizam estratégias desde cima, entretanto, apresentam uma importante diferença em relação às organizações formais. As atividades ilegais devem integrar a visão desde baixo, pelo fato de estarem sujeitas a uma maior exposição ao risco no território. A articulação e o êxito dos negócios ilegais são intensamente dependentes de conexões locais, aproveitando-se de complexos e instáveis sistemas de informação e telecomunicação, nesse movimento o macro e o micro devem estar proferidos de tal forma que possam fazer fluir tais fluxos de drogas. E de acordo com Machado (2003, p. 6):

Não há dúvida que uma das principais atrações do ilegal para a massa de trabalhadores informais (imigrantes, comerciantes ambulantes, microempresários, trabalhadores autônomos, artesãos, subcontratados etc.) é a percepção de que possa ser uma via de ascensão social, com acesso rápido às benesses do consumo, reais ou ilusórias.

Muitas vezes, articulando máfias à escala mundial, as redes ilegais podem ser vistas, ao mesmo tempo, como produtos - à margem do sistema "legal", impondo-se como forma de sobrevivência de grupos excluídos e como produtoras da desterritorialização - ao promoverem a instabilidade e a violência (HAESBAERT, 2002, p. 183).

Por fim, a Amazônia fragiliza-se diante das ações de organizações criminosas sobre a região, assim como, fragiliza-se também diante da possibilidade de se estabelecer o "estado de exceção", dado as proporções dos impactos socioespaciais e territoriais que o crime organizado pode resultar no espaço brasileiro. As cidades ou metrópoles da região amazônica tornaram-se espaços privilegiados para o narcotráfico constituir relações de poder sobre as suas periferias, favelas, baixadas etc. Estes poderes associam-se a uma relação multiescalar de 


\section{Aiala Colares COUTO}

autoridade que agrega o macro e o micro dentro de um único contexto, mas com dimensões espaciais diferenciadas.

\section{CONSIDERAÇÕES FINAIS}

O narcotráfico presente em território brasileiro vem conseguindo se firmar enquanto uma das atividades do crime organizado que causa grandes impactos sócio-políticos, sobretudo nas grandes metrópoles. Ele cria suas bases operacionais a partir de enclaves territoriais, utilizando-se de estratégias das mais variadas possíveis e sua conexão em redes têm possibilitado relações que envolvem múltiplas escalas de poder. Escalas estas que integram o local ao global e que constituem a organização espacial criada a partir das necessidades da economia do crime.

A Amazônia brasileira cumpre importante função geográfica de conectividade do narcotráfico em nível nacional e internacional, pois ela representa uma área de trânsito da cocaína produzida nos países da Comunidade Andina, recebendo toda a atenção necessária do crime organizado e sendo utilizada como corredor de importação/exportação de cocaína, transforma-se em objeto de interesse dos altos comandos do crime organizado.

Os estudos sobre a atuação do crime organizado na Amazônia brasileira pouco ou nenhuma importância tem dado aos territórios-rede ou territórios em redes do narcotráfico sobre a região. Com efeito, a Geografia passa a ter a responsabilidade em apresentar uma discussão acerca destas perspectivas de organização do crime sobre e pelo espaço a partir das relações de poder que se sobrepõe à clássica visão de território do Estado vinculado à soberania política.

Os destaques que as redes ilegais atribuem à região amazônica tornaram-na a rota primária ou área de trânsito obrigatório para os narcotraficantes dos países Andinos no que tange a distribuição de cocaína que abastece os mercados brasileiro, europeu e africano. Ou seja, uma força externa que exerce comando e controle sobre uma atividade que envolve um mercado global, e, portanto, tornando-se uma ameaça transnacional.

As fronteiras da Amazônia tornaram-se desprotegidas diante da ação do narcotráfico, e esta atividade ilícita que torna as fronteiras vulneráveis diante de suas ações, permite também, alimentar outros tipos de crimes, a exemplo do tráfico de armas e da lavagem de dinheiro, e outras atividades que para existirem dependem do seu funcionamento a partir de uma rede de articulações, que contribuem também para a territorialidade do crime organizado nas cidades brasileiras. 


\section{Aiala Colares COUTO}

Por fim, é necessário continuar aperfeiçoando estratégias de cooperação entre os países da Amazônia internacional com o intuito de formular intervenções em zonas de fronteiras, voltadas para a construção da cidadania e respeitando as especificidades de cada lugar, considerando a diversidade que há nas relações sociais quando se refere em uma região múltipla, complexa e dinâmica como a Amazônia. A fragilidade ou precariedade das ações do Estado aos poucos vai permitindo esta territorialidade em rede que se materializa e se manifesta na região reestruturando e atribuindo funções às cidades. Cabe ao Estado elaborar políticas públicas que impeçam o fortalecimento do narcotráfico em seu território.

\section{REFERÊNCIAS}

BECKER, B. A. Amazônia: geopolítica na virada do III milênio. Rio de Janeiro: Garamond, 2006.

. A geografia e o resgate da geopolítica. Revista Brasileira de Geografia, Rio de Janeiro, ano 50, t. 2, p. 99-125, 1988. Edição especial.

A geografia e o resgate da geopolítica. Revista Brasileira de, T. Tecnologia é sociedade: contra a noção de impacto tecnológico. In: DIAS, Leila Christina; SILVEIRA, Rogério Leandro Lima. (Org.). Redes, sociedades e territórios. Santa Cruz do Sul: EDUNISC, 2005.

Geopolítica da Amazônia. Estudos Avançados, n. 19, 2005. Disponível em: <http://www.scielo.br/pdf/ea/v19n53/24081.pdf/>. Acesso em: 10 mar. 2008.

. Geopolítica da Amazônia. Revista Estudos Avançados, São Paulo, v. 19, n. 54, 2006.

BRUNET, R. Zones franches et paradis fiscaux. Paris: Fayard-Reclus, 1992.

CALDERÓN, E. La lucha de Brasil contra el narcotráfico en la frontera con Colombia. Un acercamiento a los condicionamientos de las amenazas no tradicionales sobre la política exterior. OBSERVAR, Lisboa, v. 5, n. 1, p. 1-14, maio/out, 2014.

CASTELLS, M. Fim de milênio. São Paulo: Paz e Terra, 1996.

FEM. Relatório sobre atividades ilegais no mercado global. Rio de Janeiro. FEM, 2011. Disponível em: 〈http://www.bbc.com/ portuguese/noticias/2016/04/160331_atividades_crime_organizado_fn>. Acesso em: 13 ago. 2010.

GIDENS, A. O Estado-nação e a violência: segundo volume de uma crítica contemporânea ao materialismo histórico. São Paulo: EDUSP, 1985. p. 23.

HAESBAERT, R. Territórios alternativos. São Paulo: Contexto, 2002.

Desterritorialização: entre as redes e os aglomerados de exclusão. In: CASTRO, I. et al. (Org.). Geografia: conceitos e temas. Rio de Janeiro: Bertrand Brasil, 1995.

O mito da desterritorialização: do fim dos territórios à multiterritorialidade. Rio de Janeiro: Bertrand Brasil, 2004. 


\section{Aiala Colares COUTO}

. Sociedades biopolíticas de in-segurança e des-controle dos territórios. In: OLIVEIRA, M. et al. (Org.). O Brasil, a América Latina e o mundo: espacialidades contemporâneas. Rio de Janeiro: Lamparina; FAPERJ; ANPEGE, 2008.

Os dilemas da globalização-fragmentação. In: HAESBAERT, R (Org.). Globalização e fragmentação no mundo contemporâneo. Niterói: UFF, 2012.

Viver no limite. Rio de Janeiro: Bertrand, 2014.

HAESBAERT, R; PORTO GONÇALVES, C. W. A nova des-ordem Mundial. São Paulo: UNESP, 2005.

INFOPEN. Levantamento nacional de informações penitenciárias. Brasília. IFOPEN, 2014. Disponível em: <http://www.justica.gov.br/noticias/mj-divulgara-novo-relatorio-do-infopen-nestaterca-feira/relatorio-depen-versao-web.pdf > . Acesso em: 21 set. 2010.

INPAD. Segundo levantamento nacional de álcool e drogas. São Paulo. INPAD, 2012. Disponível em: 〈http://inpad.org.br/wp-content/uploads/2014/03/Lenad-II-Relat\%C3\%B3rio.pdf>. Acesso em: 21 set. 2010

ISHIDA, E. Política de segurança integrada da Amazônia: utopia ou realidade? Santiago Dantas, 2006.

JORNAL AMAZÔNIA. Caderno Polícia. Facção leva a pior em guerra com a PM. Belém, 25 ago. 2016.

. Caderno Polícia. São 30 mortos após morte de policial. Belém, 22 jan. 2017.

JORNAL O LIBERAL. Caderno Polícia. Polícia prende 14 traficantes por dia. Belém, 27 jun. 2016. jan. 2016.

Caderno Polícia. Secretário admite atuação de grupos de extermínio em Belém. Belém, 24

KOLK, Ans. Forests in International Environmental Politics. Utrecht: International Books, 1996.

MACHADO, L. O. Limites e fronteiras: da alta diplomacia aos circuitos da legalidade. Território, Rio de Janeiro, v. 5, n. 8, jan-jun. 2000.

Movimento de dinheiro e tráfico de drogas na Amazônia. In: RIBEIRO, M. M; SEIBEL, S. (Org.). Drogas: hegemonia do cinismo. São Paulo: Memorial, 1997.

FINEP, 1998.

Notas sobre o complexo coca: cocaína na Amazônia sul: Americana. In: Relatório CNPQ,

O comércio ilícito de drogas e a geografia da integração financeira: uma simbiose? In: CASTRO, I. et al. (Org.). Brasil: questões atuais da reorganização do território. Rio de Janeiro: Bertrand Brasil, 1996.

Região, Cidades e Redes Ilegais. Geografias Alternativas na Amazônia Sul-amaricana. In: GONÇALVES, Maria Flora; BRANDÃO, C. (Org.). Regiões e cidades: cidades nas regiões. São Paulo: EdUNESP, 2003. 


\section{Aiala Colares COUTO}

MACHADO, R.. Introdução: por uma genealogia do poder. In: FOUCAULT, Michel. Microfísica do poder. Rio de Janeiro: Graal, 1979. p. VII-XXIII.

MANNING, P. K. Metaphors of organizacional discourse. Administrative Science Quartely, v. 24, n. 4, dez. 1979.

MARINHO, H. J. O estudo das relações Internacionais: teorias e realidades. São Paulo: Aduaneira, 2008.

MARTIN, R. Teoria econômica e geografia humana. In: GREGORY, D; MARTIN, R; SMITH, G (Org.). Geografia humana: sociedade, espaço e ciência social. Rio de Janeiro: J. Zahar, 1997.

NOVAES, A. Tráfico de drogas e lavagem de dinheiro: um estudo sobre a atuação das redes ilegais na Amazônia brasileira. Rio de Janeiro: UFRJ, 2003.

PROCÓPIO FILHO, A; VAZ, A. C. O Brasil no contexto do narcotráfico Internacional. Rev. Bras. Polít. Internacional, v. 40, p. 78, [1997].

PROCÓPIO, A. Drogas ilícitas em espaços transfronteiriços. Revista Cena Internacional, v. 2, n. 1, p. 92-122, 2000.

RAFFESTIN, C. Por uma geografia do poder. São Paulo: Ática, 1991;1993.

RANDOLPH, R. Sociedade em rede: paraíso ou pesadelo? Reflexões acerca das novas formas de articulação social e territorial das sociedades. Revista Geografias, ano 1, n. 2, p. 27-53, 1999.

RODRIGUES, T. A infindável guerra norte-americana: Brasil, EUA e o narcotráfico no continente. São Paulo em Perspectiva, v. 2, n. 16, p. 102-111, 2002.

Narcotráfico: uma guerra na guerra. São Paulo. Desatino, 2004.

RURHOFF, A. L. Geopolítica das drogas. Santa Maria: UFSM, 1998.

SANTANA, A. A globalização do narcotráfico. Revista Brasileira de Política Internacional, v. 2, n. 42, p. 99-116, 1999.

SOUZA, T. S. A economia das drogas em uma abordagem heterodoxa. Dissertação (Mestrado). Instituto de Economia, Universidade Estadual de Campinas, Campinas, 2015

TELLES, V. S. A cidade nas fronteiras do legal e ilegal. Belo Horizonte. Argvmentvm, 2010.

UNODC. O relatório mundial sobre drogas. Washington: UNODC, 2008. Disponível em: $<$ http://www.soi.org.br/upload/4f408c d511eede14f87cb973fb8fb 6bd80b68 76225b7b71ca4c7 aa4e634c4106.pdf $>$. Acesso em: 21 set. 2010.

O relatório mundial sobre drogas. Washington: UNODC, 2012. Disponível em: $\langle$ http://www.unodc.org/lpo-brazil/pt/frontpage/2012/06/26-press-release-WDR-2012.html>. Acesso em: 21 set. 2010.

O relatório mundial sobre drogas. Washington: UNODC, 2013. Disponível em: <http://www.unodc.org/lpo-brazil/pt/frontpage/2013/06/26-world-drug-report-notes-stability-in-useof-traditional-drugs-and-points-to-alarming-rise-in-new-psychoactive-substances.html.> Acesso em: 21 set. 2010 
O relatório mundial sobre drogas. Washington: UNODC, 2014. Disponível em: <https://www.unodc.org/lpo-brazil/pt/frontpage/2014/01/13-new-unodc-campaign-raises-consumerawareness-of-links-between-organized-crime-and-250-billion-a-year-counterfeit-business.html>. Acesso em: 21 set. 2010.

O relatório mundial sobre drogas. Washington: UNODC, 2015. Disponível em: <http:// www.unodc.org/documents/wdr2015/ World_Drug_Report_2015.pdf.>. Acesso em: 21 set. 2010.

O relatório mundial sobre drogas. Washington: UNODC, 2016. Disponível em: <https://www.unodc.org/doc/ wdr2016/WORLD_DRUG_REPORT_2016_web.pdf $>$. Acesso em: 21 set. 2010. 